\title{
Transitional cell carcinoma metastasizing to an atrial myxoma
}

\author{
Ian Hunt, MRCS, Wahed Jamal, MRCS, Anoushka Chaudhry, MRCS, and James C. Roxburgh, FRCS, \\ London, United Kingdom
}

A

lthough metastatic tumors are the most common cause of malignant tumors of the heart, transitional cell carcinoma metastasizing to the heart is rare. ${ }^{1}$ The findings of metastatic deposits within an atrial myxoma are exceptionally rare, and this is the first reported case of any malignant tumor metastasizing to a myxoma.

\section{Clinical Summary}

We present the case of a 75-year-old white man presenting with acute dyspnea, who was found to have a left atrial myxoma on transthoracic echocardiography. Before surgical intervention, the patient had nonspecific complaints of lethargy and felt generally quite unwell but had no other specific symptoms or clinical signs of malignancy, urologic or otherwise. At the operation, the tumor was excised through a transverse right atrial incision and sent for pathologic investigation. The patient was taken to the intensive treatment unit for postoperative respiratory support. Once conscious, he was noted to have a paralyzed left leg. Computed tomography of the abdomen and pelvis demonstrated ascites, atrophic kidneys, and widespread lymphadenopathy, which might have resulted in monoparesis of the left leg. Results of computed tomography of the head were normal.

On histologic examination, the specimen consisted of a firm, well-circumscribed, gelatinous mass measuring $1.2 \times 3.1 \times 3.4 \mathrm{~cm}$ with features of a typical, albeit degenerate, atrial myxoma (Figure 1). In addition, there was evidence of metastatic carcinoma, with tumor cells within the vascular spaces and frequent mitoses (Figure 2). Glandular luminal openings were seen that were suggestive of adenocarcinoma or transitional cell carcinoma, and the results of immunohistochemistry were strongly positive for cytokeratin 7 and cytokeratin 20 , thus suggesting the primary tumor was most likely a transitional cell carcinoma. Tumor markers for the thyroid, prostate, and lung were negative, but urine cytology was positive for malignant cells.

Because of poor functional status and advanced disease, the patient was not considered to be suitable for radical chemotherapy or radiotherapy.

From St Thomas' Hospital, London United Kingdom.

Received for publication Jan 26, 2005; accepted for publication Feb 3, 2005.

Address for reprints: Ian Hunt, MRCS, Cardiothoracic Surgery Centre, St Thomas' Hospital, London SE1 7EH, United Kingdom (E-mail: ian.hunt@ gstt.nhs.uk).

J Thorac Cardiovasc Surg 2005;130:575-6

$0022-5223 / \$ 30.00$

Copyright $\odot 2005$ by The American Association for Thoracic Surgery

doi:10.1016/j.jtcvs.2005.02.017

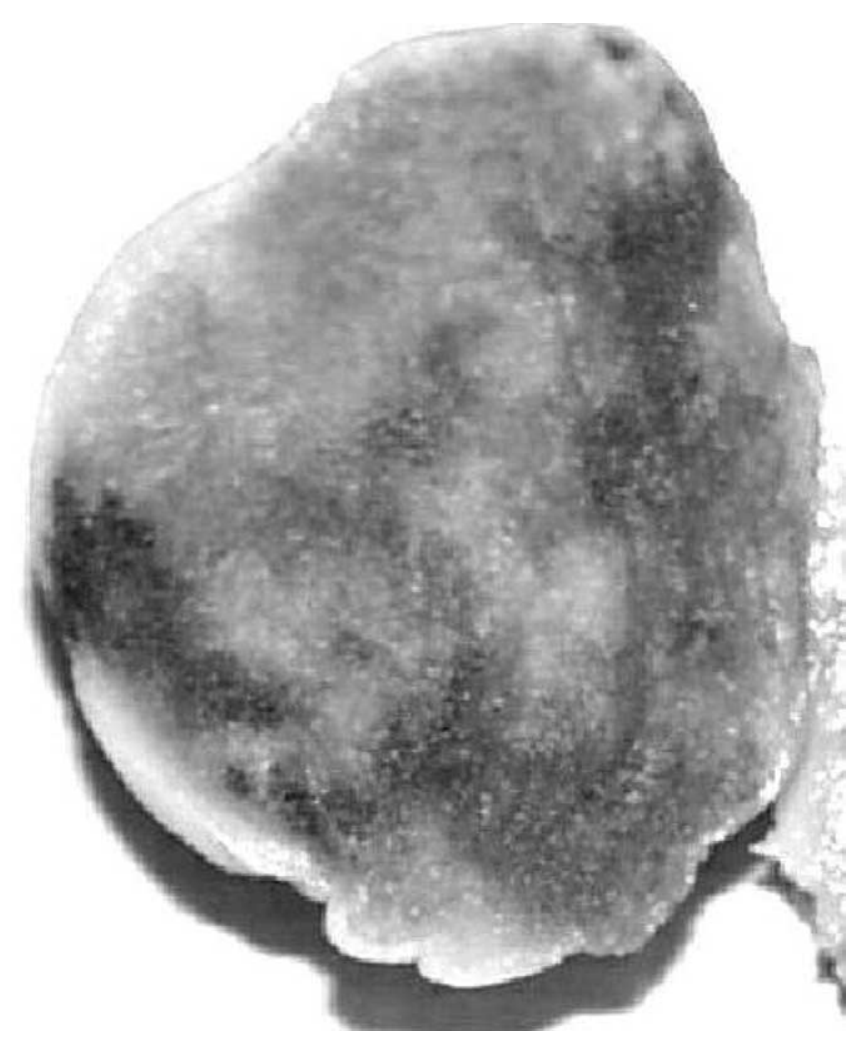

Figure 1. Cut surface of atrial myxoma illustrating the typical gelatinous appearance.

\section{Discussion}

Tumors of the heart are rare, with most being benign, of which myxomas are the most common. Malignant tumors of the heart are usually metastatic in origin, typically arising from the lung or breast, in lymphomas and with melanomas. Although most metastasizing tumors have been described with a varying incidence in the literature, ${ }^{2}$ it is extremely uncommon that cardiac metastases from transitional cell carcinoma are reported. ${ }^{1}$

The findings of metastatic tumor within the atrial myxoma was both unexpected and, in fact, very uncommon. It was only after the operation, when the patient experienced an unusual complication of left leg monoparesis, that further investigations revealed the extent of the advanced malignant process. Metastatic tumor deposits are not thought to be unusual in the heart at autopsy in patients with cancer $(5 \%)$, but clinical manifestations are rare. ${ }^{3} \mathrm{We}$ have found no other cases in the literature of metastatic tumor within an atrial myxoma, only cases of metastases mimicking myxoma. $^{4,5}$ 


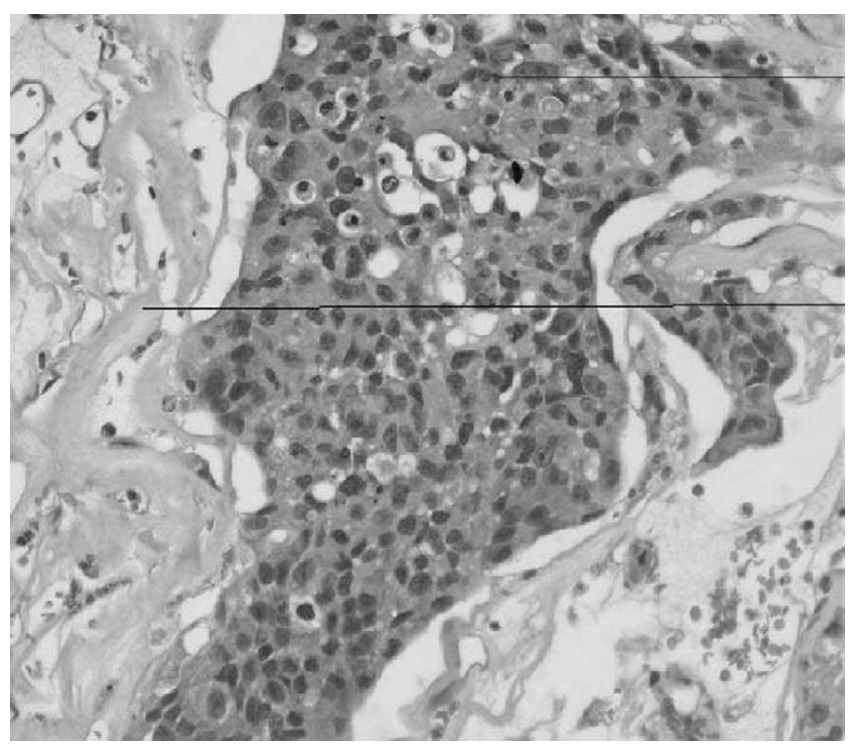

Figure 2. High-power resolution image of metastatic tumor cells (upper line) within the matrix of atrial myxoma cells (lower line).
A high index of clinical suspicion is necessary to determine the exact nature of heart tumors to optimize management of the patient.

\section{References}

1. Clemente LM, Patier JL, Lopez-Suanzes MJ, Jimenez M. Cardiac metastases form a transitional cell carcinoma: an unusual clinical manifestation. Br J Urol. 1997;80:831-2.

2. McAllister HA, Fenoglio JJ Jr. Tumors of the cardiovascular system. In: Atlas of tumor pathology, series 2. Washington (DC): Armed Forces Institute of Pathology; 1978.

3. Silverman NA. Primary cardiac tumors. Ann Surg. 1980;91:127-38.

4. Miyamoto MI, Picard MH. Left atrial mass caused by metastatic renal cell carcinoma: an unusual site of tumour involvement mimicking myxoma. $J$ Am Soc Echocardiogr. 2002;15:847-8.

5. Lang RM, Borow KM, Neumann A. Metastatic carcinoma involving the left atrium. Am Heart J. 1985;110:884-6.

\section{Endovascular treatment of a bleeding aortic aneurysm after descending aortic aneurysm repair with island reimplantation}

Petr Symersky, MD, ${ }^{a}$ Joris W. J. Vriend, MD, ${ }^{\mathrm{b}}$ Anje M. Spijkerboer, MD, PhD, ${ }^{\mathrm{c}}$ Barbara J. M. Mulder, MD, PhD, ${ }^{\mathrm{b}}$

Dink A. Legemate, MD, PhD, ${ }^{d}$ and Bas A. J. M. de Mol, MD, PhD, ${ }^{a}$ Amsterdam, The Netherlands

I ntercostal artery patch dilatation is uncommon after replacement of the descending aorta. It has been reported in patients with intrinsic aortic wall disease and may be challenging to manage in an emergency setting. ${ }^{1,2}$ We report the case of a patient with a rupture of an intercostal artery patch managed with an endovascular technique.

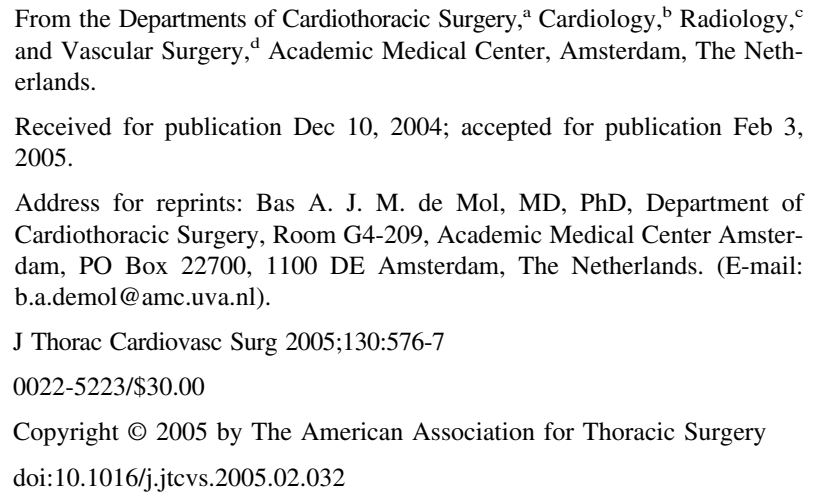
Cardiothoracic Surgery, Room G4-209, Academic Medical Center Amsterdam, PO Box 22700, 1100 DE Amsterdam, The Netherlands. (E-mail: b.a.demol@amc.uva.nl).

J Thorac Cardiovasc Surg 2005;130:576-7

$0022-5223 / \$ 30.00$

Copyright $\odot 2005$ by The American Association for Thoracic Surgery doi:10.1016/j.jtcvs.2005.02.032

\section{Clinical Summary}

A 47-year-old man with Marfan syndrome was referred for evaluation of a right-sided hemothorax. Three years previously, a type 2 thoracoabdominal aneurysm with a chronic type B dissection had been found, and the patient had undergone aortic replacement from the left subclavian artery up to the iliac arteries. A knitted Dacron vascular graft (Gelseal; Vascutek Ltd, Inchinnan, UK) was implanted with a patch containing seven intercostal arteries; another patch contained the visceral and right renal arteries, and a separate Dacron graft was connected to the left renal artery. After discharge, the patient refused follow-up computed tomographic (CT) scans.

The patient was seen with acute, tearing pain between the shoulders. At presentation, the patient was in respiratory distress and markedly hypertensive. A CT scan showed dilatation of the intercostal patch with a hematoma and primarily a right-sided pleural effusion without a clear bleeding site. Aggressive blood pressure control was instituted. After 3 days, the patient's condition deteriorated, with hemodynamic instability. Another CT scan showed a bleeding false aneurysm with a cephalad blowout of the intercostal patch (Figure 1). In an emergency setting, a Gore TAG 